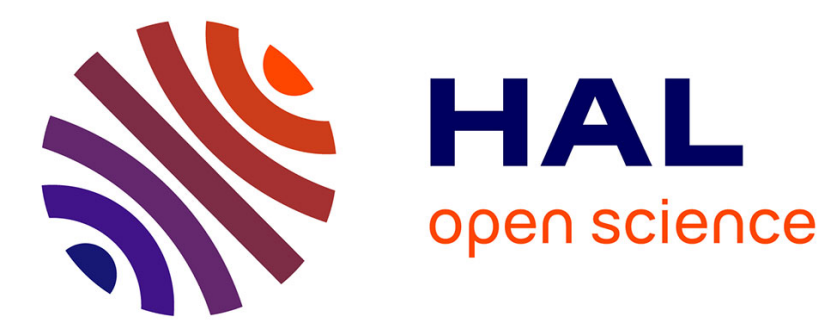

\title{
Multifunctional Photodetectors Based on Nanolayered Black Phosphorus/SnS0.5Se1.5 Heterostructures
}

Xin Luo, Bochong Wang, Wenxing Lv, Yan Wang, Weiming Lv, Zhongming Wei, Yuan Lu, Zhongyuan Liu, Zhihong Lu, Rui Xiong, et al.

\section{To cite this version:}

Xin Luo, Bochong Wang, Wenxing Lv, Yan Wang, Weiming Lv, et al.. Multifunctional Photodetectors Based on Nanolayered Black Phosphorus/SnS0.5Se1.5 Heterostructures. ACS Applied Nano Materials, 2019, 2, pp.3548. 10.1021/acsanm.9b00513 . hal-02388074

\section{HAL Id: hal-02388074 https://hal.science/hal-02388074}

Submitted on 12 Dec 2019

HAL is a multi-disciplinary open access archive for the deposit and dissemination of scientific research documents, whether they are published or not. The documents may come from teaching and research institutions in France or abroad, or from public or private research centers.
L'archive ouverte pluridisciplinaire HAL, est destinée au dépôt et à la diffusion de documents scientifiques de niveau recherche, publiés ou non, émanant des établissements d'enseignement et de recherche français ou étrangers, des laboratoires publics ou privés. 


\title{
Multifunctional Photodetectors Based on Nanolayered Black
}

\section{Phosphorus/SnS0.5Se1.5 Heterostructures}

Xin Luo ${ }^{\dagger,}$, Bochong Wang ${ }^{\S}$, Wenxing Lv ${ }^{\dagger}$, Yan Wang॥, Weiming $\mathrm{Lv}^{\dagger}$, Zhongming Wiell, Yuan $\mathrm{Lu}^{\mathrm{f}}$, Zhongyuan $\mathrm{Liu}^{\S}$, Zhihong $\mathrm{Lu}^{\perp}$, Rui Xiong ${ }^{* \ddagger}$, and Zhongming Zeng ${ }^{* \dagger}$

${ }^{\dagger}$ Key Laboratory of Nanodevices and Applications, Suzhou Institute of Nano-tech and Nano-bionics, Chinese Academy of Sciences, Ruoshui Road 398, Suzhou 215123, China

$\$$ Key Laboratory of Artificial Micro- and Nano-structures of Ministry of Education, School of Physics and Technology, Wuhan University, Wuhan 430072, People's Republic of China

${ }^{\S}$ Key Laboratory for Microstructural Material Physics of Hebei Province, School of Science, Yanshan University, Qinhuangdao 066004, China

"State Key Laboratory of Superlattices and Microstructures, Institute of Semiconductors, Chinese Academy of Sciences \& College of Materials Science and Opto-Electronic Technology, University of Chinese Academy of Sciences, Beijing 100083, China

fInstitut Jean Lamour, UMR 7198, CNRS-Université de Lorraine, BP 239, Vandœuvre 54506, France ${ }^{\perp}$ The State Key Laboratory of Refractories and Metallurgy, School of Materials and Metallurgy, Wuhan University of Science and Technology, Wuhan 430081, People's Republic of China

\begin{abstract}
Van der Waals (vdW) heterostructures have recently emerged as a promising artificial structure for nano-electronic and optoelectronic applications. In this work, we present electronic and phototransistor properties of $\mathrm{BP} / \mathrm{SnS}_{0.5} \mathrm{Se}_{1.5}$ heterostructures. The backward diode behavior in the output characteristics reveal that the heterojunction is type-III broken-gap band alignment. Moreover, an unusual gate tuned plus-minus photoresponse characteristic is demonstrated. The positive photocurrent emerges at negative gate, while a negative photocurrent appears when a positive gate is applied. In addition, this effect can be tuned by the channel length of each material. Such devices demonstrate a promising potential in future electronic and optoelectronic applications.
\end{abstract}

KEYWORDS: heterostructures, black phosphorus, negative photocurrent, gate tuned. 
Since the discovery of graphene, two-dimensional (2D) materials become as an attractive research topic due to the rich fundamental physics and wide application potential. ${ }^{1-3}$ However, the characteristic of graphene with zero bandgap restricts its extensive prospect to surpass the traditional semiconductor devices, such as p-n junction transistors and logic circles. ${ }^{4}$ Therefore, active research interest arises in the area of transition-metal dichalcogenides (TMDCs) that possess tunable bandgap. ${ }^{5,6}$ For instance, the band gap of $\mathrm{MoS}_{2}$ can change from indirect to direct bandgap as the thickness decreases from bulk towards single layer, and it also shows good mobility and on/off ratios. ${ }^{5}$ As time goes on, black phosphorus (BP) is paid close attention because of its tunable direct band gap ranging from $\sim 0.3 \mathrm{eV}$ for bulk to $\sim 2 \mathrm{eV}$ for monolayer and excellent electronic property. ${ }^{7-9}$

Recently, van der Waals (vdW) heterostructures composed of 2D layered materials have become as a novel artificial structure family that exhibits many new physics phenomena and function. ${ }^{10-20}$ Unlike usual three-dimensional (3D) semiconductor heterostructures with strict and difficult epitaxy growth, high-quality 2D heterostructures can be easily created by stacking kinds of nanoflakes as the absence of lattice mismatch and dangling bonds on surface. ${ }^{17}$ Among the vdW heterostructures, photodetective heterostructures with simple fabrication, wide detective range, and excellent performance have been studied. $^{21-31}$ The $\mathrm{BP} / \mathrm{MoS}_{2}$ heterostructure displays detective ability from visible to near-infrared light owing to the combination of two materials. ${ }^{21}$ The ultraviolet to near-infrared photodetector of $\mathrm{p}-\mathrm{GaSe} / \mathrm{n}$ InSe vdW heterostructure contacted with graphene shows fast rise and decay time $(\sim 2 \mu \mathrm{s}) .{ }^{22}$ As a result, multiple 2D materials association in a device can be employed to realize better photoresponsive performance, indicating a heterostructure of new incorporation may present a combined effect. Lately, the photoresponsive behavior of BP has also been focused. ${ }^{32,33}$ Negative photocurrent of BP device is discovered due to the decrease in conductivity when heated by optical absorption. ${ }^{33}$ The photoresponsivity reaches a high value of nearly $100 \mathrm{~A} / \mathrm{W}$ when at $-4 \mathrm{~V}$ gate voltage with a laser wavelength of $830 \mathrm{~nm}$. On the other hand, n-type SnSSe exhibits excellent phototransistor performance of $4480 \mathrm{~A} / \mathrm{W}$ for the $633 \mathrm{~nm}$ irradiation at $0.326 \mathrm{~mW} / \mathrm{cm}^{2}$ with a $10 \mathrm{~V}$ bais voltage. ${ }^{34} \mathrm{SnS}_{0.5} \mathrm{Se}_{1.5}$ which also belongs to the ternary $2 \mathrm{D}$ crystal $\mathrm{SnS}_{2-\mathrm{x}} \mathrm{Se}_{\mathrm{x}}$ system would display better photocurrent property. ${ }^{35}$ The combination of two materials would demonstrate novel photoresponsive property. However, there is no report on $\mathrm{BP} / \mathrm{SnS}_{0.5} \mathrm{Se}_{1.5}$ heterostructures.

In this study, we report the electrical transport and photoresponsive properties of vdW heterostructures assembled of $\mathrm{SnS}_{0.5} \mathrm{Se}_{1.5}$ and BP. Tunneling electron effect was found in the devices. 
The appearance of transfer curve relates with the existence of illumination. An unusual gate tuned phototransistor is observed, i.e. a gate tuned plus-minus phototransistor. Under negative gate, positive photocurrent appears and photoresponsivity can be modified. When a positive gate is applied, photocurrent becomes negative and can be also tuned by the gate.. Moreover, the photoresponsive property can be modulated by the channel length. Our results demonstrate a promising heterostructure for electronic and optoelectronic devices.

\section{RESULTS AND DISCUSSION}

Figure 1a demonstrates the schematic diagram of vdW heterostructure consisting of few-layer $\mathrm{SnS}_{0.5} \mathrm{Se}_{1.5}$ and $\mathrm{BP}$ on the $\mathrm{HfO}_{2} / \mathrm{Si}$ substrate. Part of $\mathrm{SnS}_{0.5} \mathrm{Se}_{1.5}$ is overlapped with BP to form the heterostructure. On the Si surface, $30 \mathrm{~nm} \mathrm{HfO} 2$ with high-k gate dielectric is used to enhance the ability of gate control. Figure $1 \mathrm{~b}$ presents an optical microscopic image of a typical heterostructure device. There are four electrodes connecting with $\mathrm{SnS}_{0.5} \mathrm{Se}_{1.5}$, named as $\mathrm{S} 1$ to $\mathrm{S} 4$, and seven electrodes connecting with BP, recorded as D1 to D7. Figure 1c shows surface morphology measured by atomic force microscope (AFM). Thicknesses of BP flake and $\mathrm{SnS}_{0.5} \mathrm{Se}_{1.5}$ flake are determined to be $15 \mathrm{~nm}$ and $10 \mathrm{~nm}$, respectively (Figure 1d). Raman spectra of $\mathrm{SnS}_{0.5} \mathrm{Se}_{1.5}$ section, BP section, and junction sections are shown in Figure 1e. The spectra peaks of $\mathrm{E}_{\mathrm{g}(\mathrm{Se}-\mathrm{Sn})}\left(122.8 \mathrm{~cm}^{-1}\right), \mathrm{A}_{1 \mathrm{~g}(\mathrm{Se}-\mathrm{Sn})}\left(192.5 \mathrm{~cm}^{-1}\right)$, and $\mathrm{A}_{1 \mathrm{~g}(\mathrm{~S}-\mathrm{Sn})}(192.5$ $\mathrm{cm}^{-1}$ ) are observed in $\mathrm{SnS}_{0.5} \mathrm{Se}_{1.5}$ section, indicating a good quality of the thin film. ${ }^{36}$ Three characteristic peaks of BP are measured and consistent with previous studies. ${ }^{21}$ All peaks in individual material present in the junction Raman results, manifesting the formation of heterojunction.

Electrical transport studies of the heterostructure device were carried out under darkness first. Figure 2a,b present the output $\left(I_{\mathrm{ds}}-V_{\mathrm{ds}}\right)$ and transfer characteristics $\left(I_{\mathrm{ds}}-V_{\mathrm{g}}\right)$ of the device, respectively. BP shows bipolar semiconductor characteristic and $\mathrm{SnS}_{0.5} \mathrm{Se}_{1.5}$ possesses $\mathrm{n}$-type property in the experiment. The transfer characteristics results of each material in the device are plotted (see Supporting Information, Figure S1). BP presents p-type behavior when applied a negative gate voltage $\left(V_{\mathrm{g}}\right)$, while $\mathrm{SnS}_{0.5} \mathrm{Se}_{1.5}$ shows n-type behavior at all range of $V_{\mathrm{g}}$. To understand the carrier transport mechanism in the heterostructure, rectification ratio as a function of $V_{\mathrm{g}}$ is shown in inset of Figure 2a. It increases slowly from 0.2 to 1.6 as $V_{\mathrm{g}}$ increases. Backward diode behavior (rectification ratio $<1.0$ ) is observed when a negative $V_{\mathrm{g}}$ is applied, which is different from the ordinary p-n junction. Such diode behavior under 
negative $V_{\mathrm{g}}$ indicates that the band arrangement at the heterojunction interface is type-III broken-gap band alignment. ${ }^{13}$

Based on these results and previous work considering a similar structure, ${ }^{13}$ the band alignment diagram near the junction is shown in Figure 2c. Under a forward bias voltage $\left(V_{\mathrm{ds}}>0 \mathrm{~V}\right)$, electrons can tunnel from the side of $\mathrm{SnS}_{0.5} \mathrm{Se}_{1.5}$ to BP. While, electrons can tunnel inversely when a reverse bias voltage $\left(V_{\mathrm{ds}}<0 \mathrm{~V}\right)$ is applied. Because of the weak rectification ability at different $V_{\mathrm{g}}$ and the backward diode behavior (inset of Figure 2a), tunneling electrons makes greater contribution to the current $\left(I_{\mathrm{ds}}\right)$ than other forms, such as electrons diffusion. In addition, the rectification ratio is higher (lower) than 1.0 when $V_{\mathrm{g}}>0\left(V_{\mathrm{g}}<0\right)$, indicating electrons tunnel more easy (hard) under forward bias compared with the case under reverse bias.

In Figure $2 \mathrm{~b}$, the trend of transfer curves $\left(I_{\mathrm{ds}}-V_{\mathrm{g}}\right)$ is not monotonous at a fixed forward bias. When a forward bias $V_{\mathrm{ds}}=0.1 \mathrm{~V}$ is applied, current transfer curves can be divided into four regions based on the $V_{\mathrm{g}}$. Current shows extreme points when $V_{\mathrm{g}}=-2 \mathrm{~V}$ and $3.5 \mathrm{~V}$. In a qualitative manner, the trend of transfer curves of heterostructure can be regarded as a superposition of the each material trend (see Supporting Information, Figure S2a). In region I $\left(-5 \mathrm{~V}<V_{\mathrm{g}}<-2 \mathrm{~V}\right)$ and region II $\left(-2 \mathrm{~V}<V_{\mathrm{g}}<0 \mathrm{~V}\right)$, the rise and fall of $I_{\mathrm{ds}}$ result from the competition of carriers in two materials. In region III $\left(0 \mathrm{~V}<V_{\mathrm{g}}<3.5\right.$ $\mathrm{V})$ and region IV $\left(3.5 \mathrm{~V}<V_{\mathrm{g}}<5 \mathrm{~V}\right)$, the increase and decrease of $I_{\mathrm{ds}}$ are caused by the change of the carriers in BP. As a result, two current peaks appear. BP in the device shows ambipolar behavior with strong p-type at negative gate and weak n-type at positive gate $\left(0 \mathrm{~V}<V_{\mathrm{g}}<3.5 \mathrm{~V}\right)$ (Supporting Information, Figure $\mathrm{S} 1 \mathrm{~b})$. Then, it presents p-type again under large gate $\left(3.5 \mathrm{~V}<V_{\mathrm{g}}<5.0 \mathrm{~V}\right)$, inferring the decrease of holes exceeds the saturated increase of electrons.

Next, the characterizations of gate modified photoresponsive properties were taken. Figure 3a shows transfer curves $\left(I_{\mathrm{ds}}-V_{\mathrm{g}}\right)$ of $\mathrm{BP} / \mathrm{SnS}_{0.5} \mathrm{Se}_{1.5}$ heterostructure under enhanced intensity of ultraviolet $(\lambda=365 \mathrm{~nm})$. In darkness, the device contains double 'on' state behavior with two peaks in transfer curve. In comparison, it shows single 'on' state characteristic as long as turning on light. At negative $V_{\mathrm{g}}$, current increases by enhancing the illumination intensity due to the rise of photo-induced carriers. This rule is also obeyed at positive gate, but it causes minus photoconductivity. In order to explain this phenomenon, we measured the photoresponsive effect of each material (Figure 3b,c). The current under light $\left(I_{\text {light }}\right)$ of $\mathrm{SnS}_{0.5} \mathrm{Se}_{1.5}$ raises with increasing the illumination intensity due to the photo-induced electrons inside. While, the $I_{\text {light }}$ of BP under positive $V_{\mathrm{g}}$ reduces compared with the dark current $\left(I_{\text {dark }}\right)$, 
i.e. the photocurrent $\left(I_{\mathrm{ph}}=I_{\text {light }}-I_{\mathrm{dark}}\right)$ is negative. The photo-induced carriers emerge in BP under light, and the recombination of holes and electrons takes place efficiently, causing the reduction of current. In view of the photoresponse appearance of each material, the heterostructure transfer characteristics under light can also be treated as the overlapping effect of each material under light (Supporting Information, Figure S2b).

Furthermore, the gate tuned photoresponsive performance is focused. The photoresponsivity $(R=$ $\left.I_{\mathrm{ph}} / P S\right)$ of the heterostructure as a function of $V_{\mathrm{g}}$ under different illumination intensity is plotted in Figure 3d, where $P$ is laser power, and $S$ stands for the effect responsive area. The data of $I_{\mathrm{ph}}$ is obtained from Figure 3a. In Figure 3d, photoresponsivity is modified by both negative and positive $V_{\mathrm{g}}$. Under negative $V_{\mathrm{g}}$, the relation of positive $R$ and $V_{\mathrm{g}}$ corresponds to the left partial of Figure $3 \mathrm{a}$. $I_{\mathrm{ph}}$ rises first and falls to zero when $V_{\mathrm{g}}$ is close to zero which results from the competition of carriers in two materials. While under positive $V_{\mathrm{g}}, I_{\mathrm{ph}}$ falls to negative value and leads to negative $R$. High photoresponsive performance appears at $V_{\mathrm{g}}=-2.4 \mathrm{~V}(203 \mathrm{~A} / \mathrm{W})$ and $V_{\mathrm{g}}=2.8 \mathrm{~V}(-450 \mathrm{~A} / \mathrm{W})$. Therefore, a gate tuned plus-minus phototransistor is presented. Besides, the dependence of detectivity $\left(D^{*}=R S^{1 / 2} /\left(2 e I_{\text {dark }}\right)^{1 / 2}\right)$ and photocurrent ratio $\left(I_{\mathrm{ph}} / I_{\text {dark }}\right)$ on $V_{\mathrm{g}}$ (see Supporting Information, Figure S3). Both can be tuned by $V_{\mathrm{g}}$. For instance, when a laser of $17.65 \mathrm{~mW} / \mathrm{cm}^{2}$ is appield, their Log results decrease linearly under minus $V_{\mathrm{g}}$ and keep invariant at a wide range of plus $V_{\mathrm{g}}$.

Finally, we focus on the gate modified photoresponsive properties in relation with different channel lengths. Transfer characteristic with increased BP channel length $\left(L_{\mathrm{BP}}\right)$ under darkness and illumination are shown in Figure 4a,b, respectively. The source electrode is fixed at electrode-S4, while drain electrode changes from electrode-D1 to electrode-D7, as marked in Figure 1b. Namely, the channel length of $\operatorname{SnS}_{0.5} \mathrm{Se}_{1.5}\left(L_{\mathrm{n}}\right)$ is fixed at $3.4 \mu \mathrm{m}$, and $L_{\mathrm{BP}}$ increases from $1 \mu \mathrm{m}$ to $12 \mu \mathrm{m}$. The Device-S4D6 representing long $L_{\mathrm{BP}}$ has been discussed above. Figure $4 \mathrm{a}$ demonstrates that the double 'on' state behavior only occurs when $L_{\mathrm{BP}}$ is long enough (i.e. Device-S4D6 and Device-S4D7). It's coordinated with the behavior explanation that BP competes $\left(V_{\mathrm{g}}<0 \mathrm{~V}\right)$ and dominates $\left(V_{\mathrm{g}}>0 \mathrm{~V}\right)$ in darkness. When the $L_{\mathrm{BP}}$ is not long adequately (i.e. Device-S4D1 $\sim \mathrm{S} 4 \mathrm{D} 5$ ), the heterostructure transistor only shows ntype owing to the dominance of $\mathrm{SnS}_{0.5} \mathrm{Se}_{1.5}$. In Figure $4 \mathrm{~b}$, the Device-S4D1 $\sim \mathrm{S} 4 \mathrm{D} 3$ only show n-type under illumination when $L_{\mathrm{BP}}$ is short. While, other devices (Device-S4D4 S4D7) behave single 'on' state. These results also follow the explanation of BP competition role $\left(V_{\mathrm{g}}<0 \mathrm{~V}\right)$ and domination role $\left(V_{\mathrm{g}}>0 \mathrm{~V}\right)$ under illumination. Figure $4 \mathrm{a}, \mathrm{b}$ shows the appearance of transfer curve bases upon $L_{\mathrm{BP}}$. The 
$L_{\mathrm{BP}}$ can determine it presents monotonous behavior or 'on' state.

The photoresponsive performances for increased $L_{\mathrm{BP}}$ are shown in Figure $4 \mathrm{c}$. When $L_{\mathrm{BP}}$ is short (Device-S4D1, Device-S4D2), the photoresponsivity increases due to the dominance of $\mathrm{SnS}_{0.5} \mathrm{Se}_{1.5}$. The photoresponsivity can be tuned from $20 \mathrm{~A} / \mathrm{W}$ to a high value of $5085 \mathrm{~A} / \mathrm{W}$ by gate control, indicating good photoresponsive behavior of n-type material in the heterostructure. For the devices with longer $L_{\mathrm{BP}}$, photoresponsivity fluctuates and negative photocurrent can also be discovered. It demonstrates the behavior of gate tuned phototransistor is influenced by the channel length. The advantage of such a device is that multiple functional phototransistor can be well controlled by simply switching the channel length in one structure without other procedure.

The photoresponsive properties with different $L_{\mathrm{n}}$ are studied. The $L_{\mathrm{BP}}$ is fixed at a long length of 12 $\mu \mathrm{m}$ and $L_{\mathrm{n}}$ increases from $1.4 \mu \mathrm{m}$ to $3.4 \mu \mathrm{m}$. In Figure $4 \mathrm{c}$, they all behave double 'on' state under darkness. In Figure 4d, the single 'on' behavior is occurred under light. Then, the $V_{\mathrm{g}}$ dependence of $R$ is shown in Figure 4f. The photoresponsive performance also can be tuned by gate and negative $R$ appears. It demonstrates the behavior of gate tuned plus-minus phototransistor. Besides, similar negative photocurrent phenomenon also happens in the other heterostructure sample (see Supporting Information, Figure S4). Its transfer curves under darkness behaves double 'on' state anti-ambipolar behavior with two peaks. While it becomes single 'on' state anti-ambipolar under illumination. Negative photocurrent occurs when a small positive gate is applied. The logic transport is also studied, and three states exist in the device (see Supporting Information, Figure S5). Under darkness, the output voltage $\left(V_{\text {out }}\right)$ doesn't decrease to minimum value. While three states behavior is found under illumination.

\section{CONCLUSION}

In summary, we demonstrate detailed photoelectric studies of the vdW heterostructure composing of $\mathrm{SnS}_{0.5} \mathrm{Se}_{1.5}$ and BP. The heterojunction shows a type-III broken-gap band alignment which is caused by electron tunneling. In darkness, the device behaves double 'on' state behavior with two peaks in transfer curve, while it becomes single 'on' state under illumination owing to the competition of two parts. This 'on' state effect shows potential in future double frequency application. At the same time, a gate tuned plus-minus phototransistor with both positive and negative photocurrent is presented. i.e. the plus photoresponsivity varies with negative gate, while the minus photoresponsivity changes under negative 
gate. Moreover, different channel lengths affects the transfer and photoresponsive property due to the dominance contention of each material. These meaningful photoresponsive phenomenon could be instructive for optoelectronics.

\section{METHODS}

Device Fabrication. $\mathrm{BP} / \mathrm{SnS}_{0.5} \mathrm{Se}_{1.5} \mathrm{vdW}$ heterostructures were obtained by all-dry deterministic transfer method. First, $30 \mathrm{~nm}$ Hafnium Oxide $\left(\mathrm{HfO}_{2}\right)$ with high- $\kappa$ dielectric grown by atomic layer deposition (ALD) was deposited on a silicon wafer. Second, thin flakes of $\mathrm{SnS}_{0.5} \mathrm{Se}_{1.5}$ and BP were mechanically exfoliated on PDMS using micromechanical cleavage approach, respectively. Third, $\mathrm{SnS}_{0.5} \mathrm{Se}_{1.5}$ was transferred from the PDMS onto $\mathrm{HfO}_{2}$ substrate under microscope (Olympus BX 51M). The binding force between nanoflake and $\mathrm{HfO}_{2}$ was stronger, so it stayed on the substrate when PDMS was peeled off. Fouth, BP was deterministically transferred from PDMS onto $\mathrm{SnS}_{0.5} \mathrm{Se}_{1.5}$. Fifth, Ni (10 $\mathrm{nm}) / \mathrm{Au}(50 \mathrm{~nm})$ metal electrodes were fabricated by electron-beam lithography and electron-beam evaporation. Finally, a drop of PMMA was dripped on the device to protect it from oxidation after liftoff process.

Device Characterization. Thickness of the flakes was determined by atomic force microscope (AFM) analysis. Raman spectra (Labram HR 800, $532 \mathrm{~nm}$ excitation laser) was used to characterize material quality. The electrical transport measurements were carried out by Keithley 2612B and 2400 at room temperature.

\section{ASSOCIATED CONTENT}

\section{Supporting Information}

Transfer characteristics of each material in the heterostructure under darkness (S1); transfer characteristics of the heterostructure, $\mathrm{SnS}_{0.5} \mathrm{Se}_{1.5}$, and $\mathrm{BP}$ under darkness and illumination (S2); complementary photoresponsive properties of the heterostructure (S3); photoresponsive properties of the other heterostructure (S4); logic properties of the heterostructure (S5).

\section{AUTHOR INFORMATION}


*E-mail: Rui Xiong (xiongrui@whu.edu.cn) and Zhongming Zeng (zmzeng2012@sinano.ac.cn)

\section{Notes}

The authors declare no competing financial interest.

\section{ACKNOWLEDGMENTS}

The authors would like to acknowledge the National Natural Science Foundation of China (Grant No. $51761145025,61622406,61571415,11474225,11774270,11574242)$. 
a
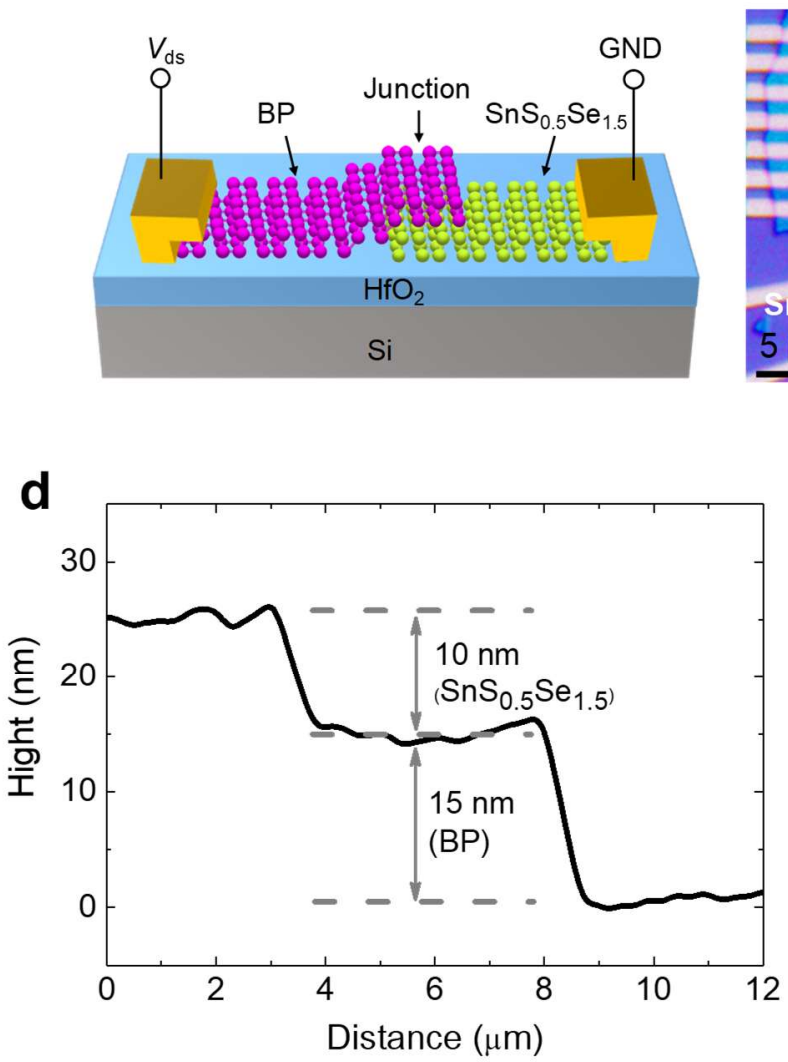

b

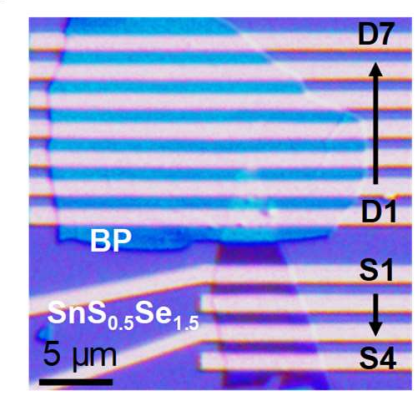

C

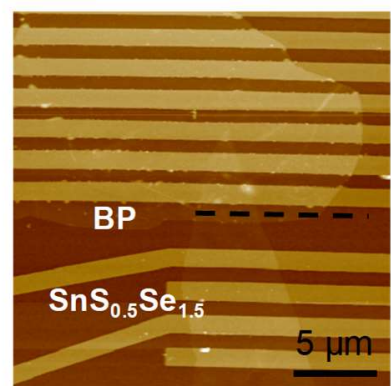

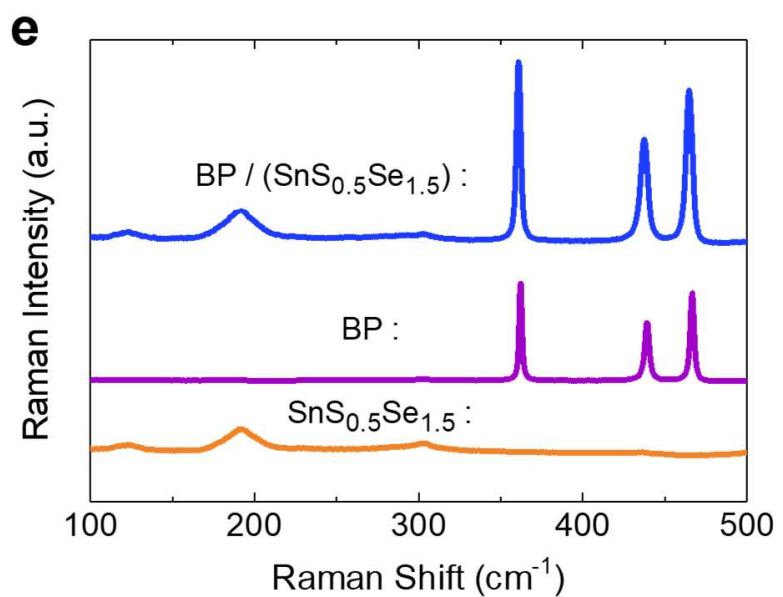

Figure 1. (a) Schematic diagram of vdW p-n heterostructure consisting of $\mathrm{BP}$ and $\mathrm{SnS}_{0.5} \mathrm{Se}_{1.5}$ on $\mathrm{HfO}_{2} / \mathrm{Si}$ substrate. (b) Optical microscopic image of heterostructure, in which the scale bar is $5 \mu \mathrm{m}$. The electrodes of $\mathrm{S} 1 \sim \mathrm{S} 4$ stand for source electrodes touching with $\mathrm{SnS}_{0.5} \mathrm{Se}_{1.5}$, and D1 $\sim \mathrm{D} 7$ represent drain electrodes contacting with BP. The source electrode is connecting to the ground (GND), and bias voltage is applied on the drain electrode. (c) AFM image of the device, in which the scale bar is $5 \mu \mathrm{m}$. (d) Height profile along black line, indicating the thickness of bottom layer $\left(\mathrm{SnS}_{0.5} \mathrm{Se}_{1.5}\right)$ and top layer (BP), respectively. (d) Raman spectra of the $\mathrm{SnS}_{0.5} \mathrm{Se}_{1.5}$ section, $\mathrm{BP}$ section , and $\mathrm{BP} / \mathrm{SnS}_{0.5} \mathrm{Se}_{1.5}$ heterojunction section. 
a

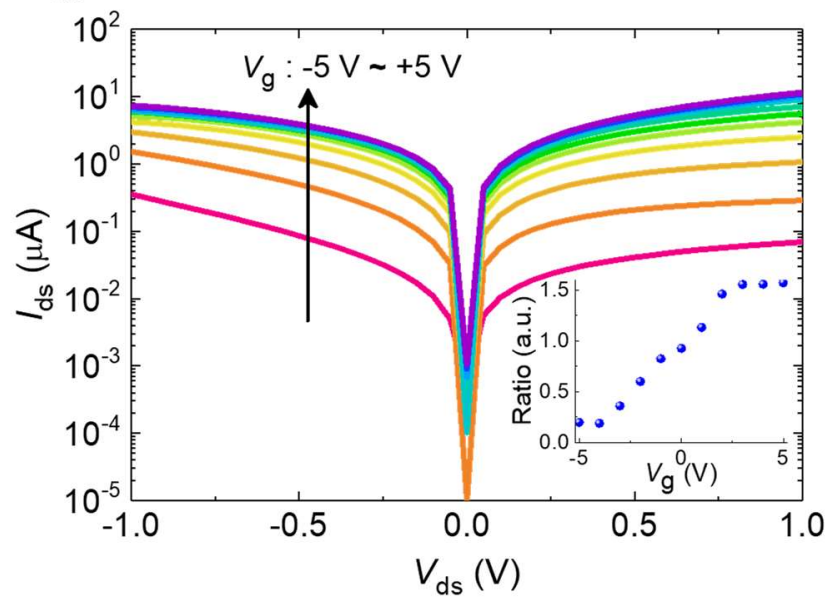

C

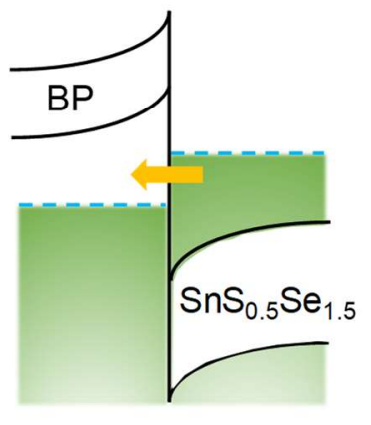

$$
V_{\mathrm{ds}}>0 \mathrm{~V}
$$

b
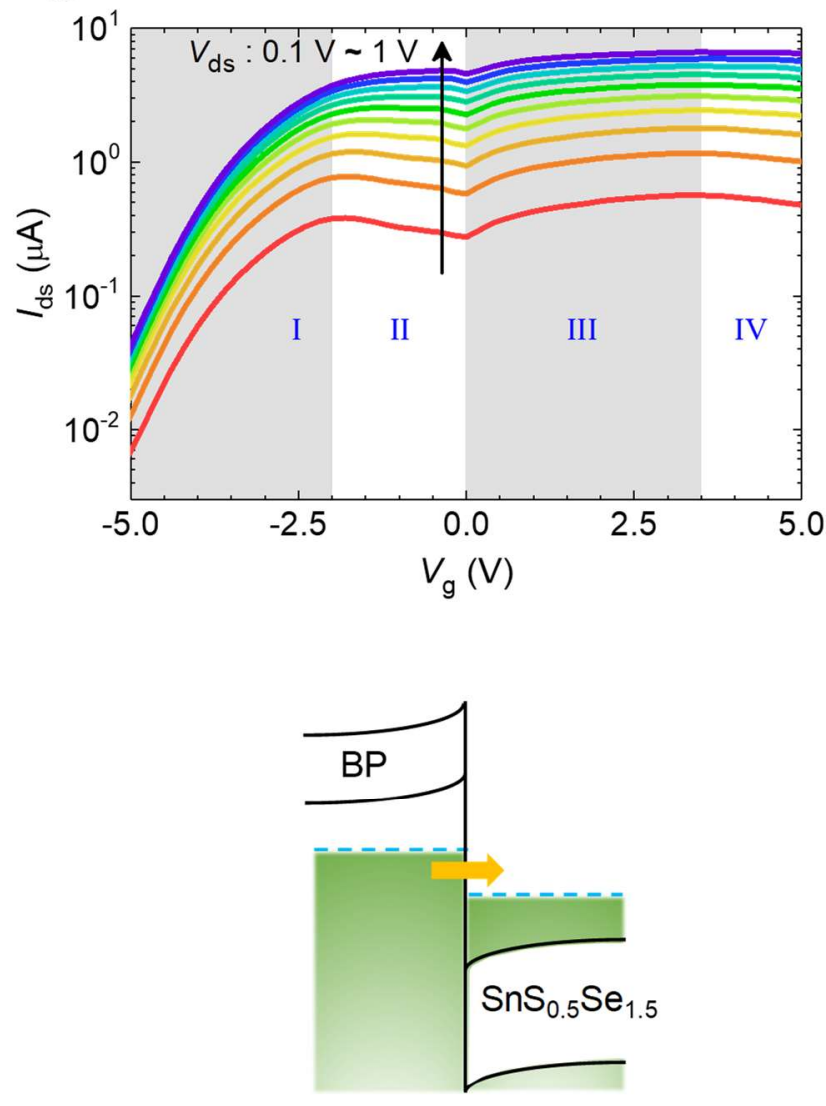

$V_{\mathrm{ds}}<0 \mathrm{~V}$

Figure 2. (a) Output results $\left(I_{\mathrm{ds}}-V_{\mathrm{ds}}\right)$ of the heterostructure between the electrode-S4 and electrode-D6 (Device-S4D6), in which the gate voltage increases from $-5 \mathrm{~V}$ to $+5 \mathrm{~V}$ (step $=1 \mathrm{~V})$. (b) Transfer characteristics $\left(I_{\mathrm{ds}}-V_{\mathrm{g}}\right)$ of the device under the same measure electrodes, in which the bias changes from $0.1 \mathrm{~V}$ to $1 \mathrm{~V}($ step $=0.1 \mathrm{~V})$. (c) The band alignment diagram near the junction. 

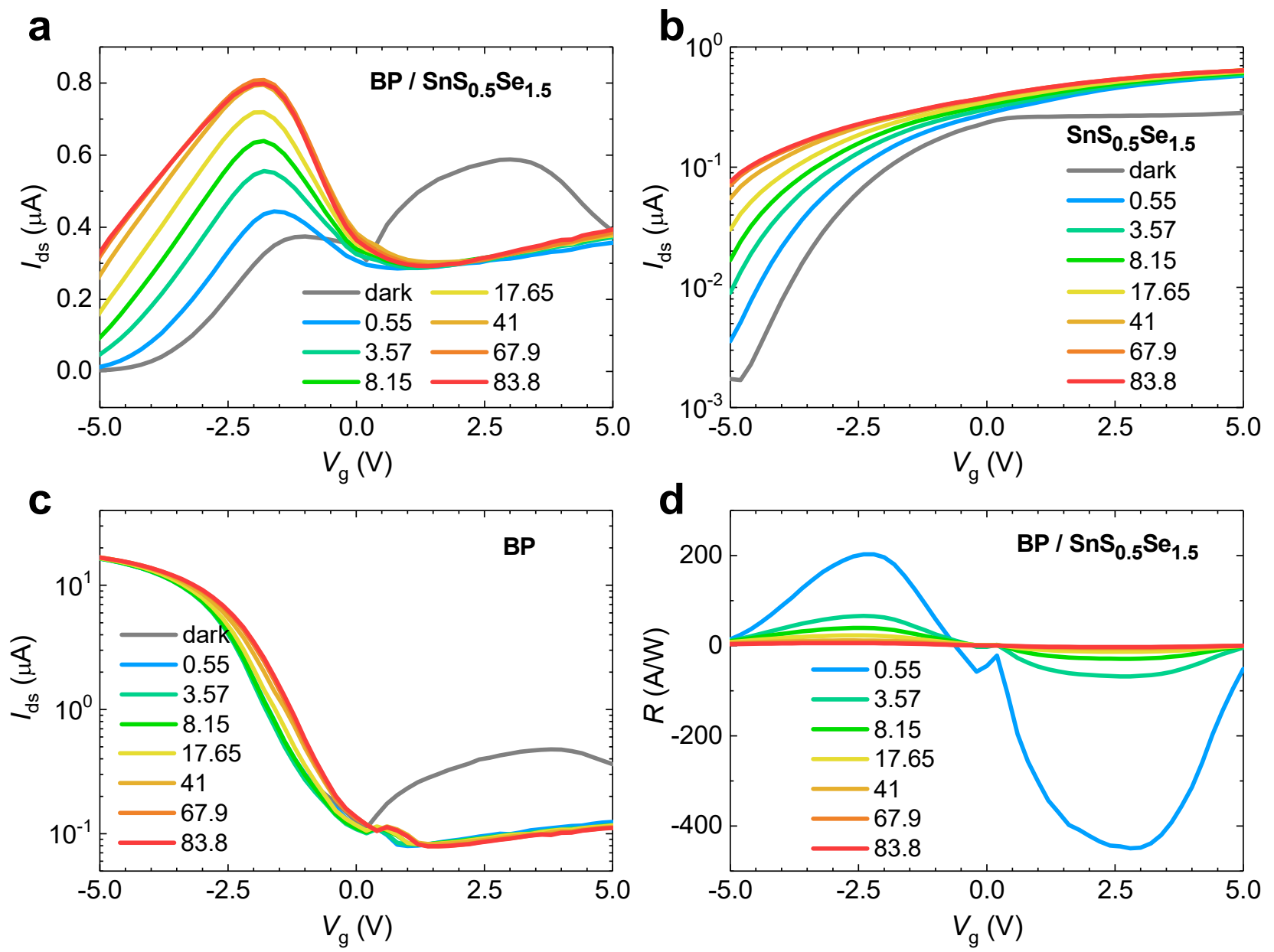

Figure 3. (a)-(c) Transfer curves of $\mathrm{BP} / \mathrm{SnS}_{0.5} \mathrm{Se}_{1.5}$ heterostructure (Device-S4D6), independent $\mathrm{SnS}_{0.5} \mathrm{Se}_{1.5}$ (Device-S1S4), and independent BP (Device-D4D7) under increased intensity of $365 \mathrm{~nm}$ laser. The laser power is increased from 0 to $83.8 \mathrm{~mW} / \mathrm{cm}^{2}$. (d) The photoresponsivity of the heterostructure as a function of gate voltage at different illumination power $\left(0.55 \mathrm{~mW} / \mathrm{cm}^{2} \sim 83.8\right.$ $\left.\mathrm{mW} / \mathrm{cm}^{2}\right)$. 

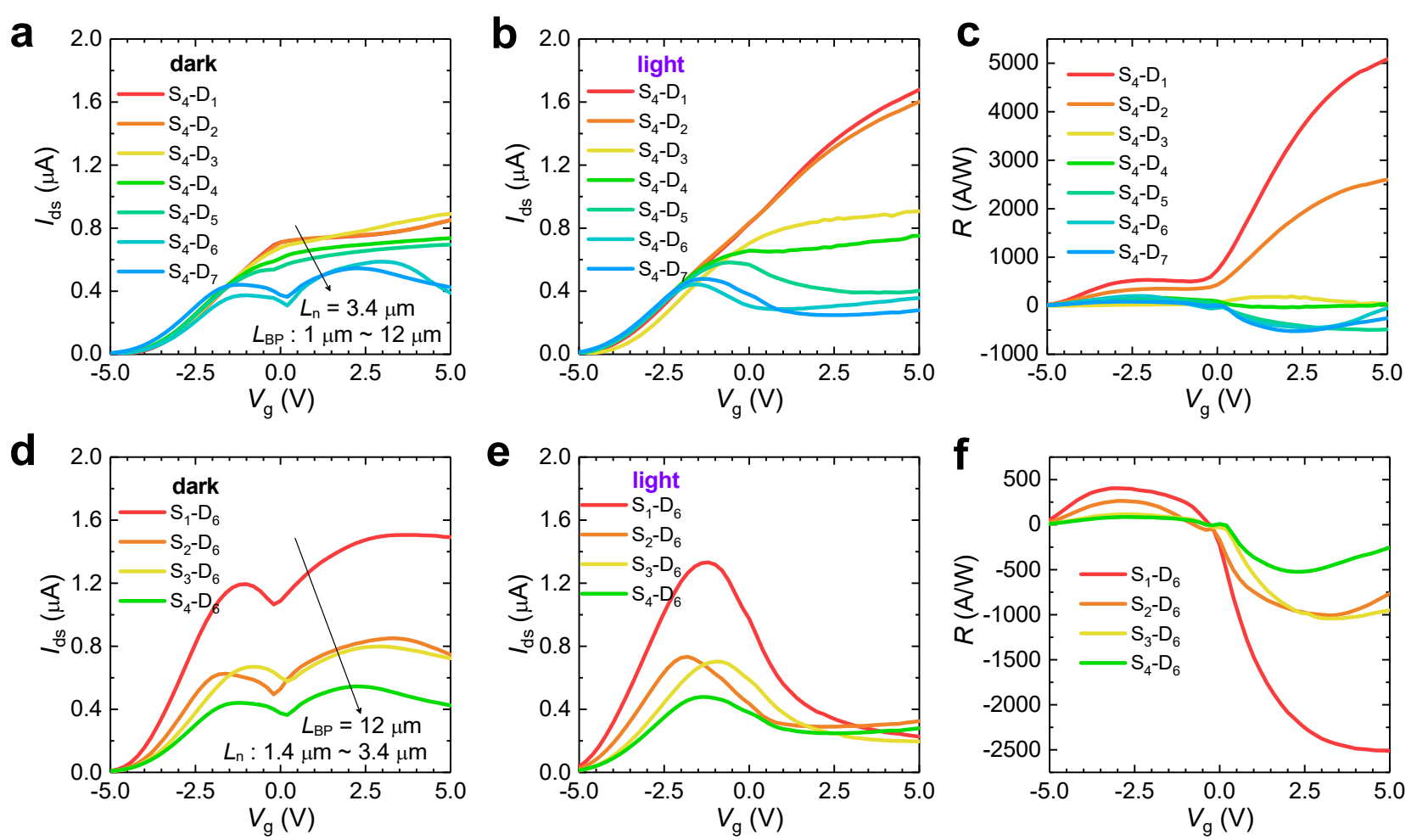

Figure 4. (a)-(b) Transfer curves of the heterostructure with increased BP channel length $\left(L_{\mathrm{BP}}\right)$ in the darkness and under illumination $\left(P=0.55 \mathrm{~mW} / \mathrm{cm}^{2}\right)$, respectively. The channel length of $\operatorname{SnS}_{0.5} \operatorname{Se}_{1.5}\left(L_{\mathrm{n}}\right)$ is $3.4 \mu \mathrm{m}$, and $L_{\mathrm{BP}}$ increases from $1 \mu \mathrm{m}$ to $12 \mu \mathrm{m}$. Bias is fixed at $0.1 \mathrm{~V}$. The range of y-axis in these two graphs is $0 \sim 2 \mu \mathrm{A}$. (c) The photoresponsivity of the heterostructure as a function of gate voltage with increased $L_{\mathrm{BP}}$ at the illumination power $P=0.55 \mathrm{~mW} / \mathrm{cm}^{2}$. (d)-(e) Transfer curves of the heterostructure with increased $L_{\mathrm{n}}$ in the darkness and under illumination $\left(P=0.55 \mathrm{~mW} / \mathrm{cm}^{2}\right)$, respectively. The channel length of $L_{\mathrm{BP}}$ is $12 \mu \mathrm{m}$, and $L_{\mathrm{n}}$ increases from $1.4 \mu \mathrm{m}$ to $3.4 \mu \mathrm{m}$. $0.1 \mathrm{~V}$ bias is applied. The range of yaxis in these two graphs is $0 \sim 2 \mu \mathrm{A}$. (f) The gate dependence of photoresponsivity with increased $L_{\mathrm{n}}$ at the illumination power of $0.55 \mathrm{~mW} / \mathrm{cm}^{2}$. 


\section{REFERENCES}

(1) Novoselov, K. S.; Geim, A. K.; Morozov, S. V.; Jiang, D.; Zhang, Y.; Dubonos, Grigorieva, I. V.; Firsov, A. A. Electric Field Effect in Atomically Thin Carbon Films. Science 2004, 306, 666-669.

(2) Chen, C. C.; Aykol, M.; Chang, C. C.; Levi, A. F.; Cronin, S. B. Graphene-Silicon Schottky Diodes. Nano Lett. 2011, 11, 1863-1867.

(3) Biswas, C.; Gunes, F.; Duong, D. L.; Lim, S. C.; Jeong, M. S.; Pribat, D.; Lee, Y. H. Negative and Positive Persistent Photoconductance in Graphene. Nano Lett. 2011, 11, 4682-4687.

(4) Yu, W. J.; Li, Z.; Zhou, H.; Chen, Y.; Wang, Y.; Huang, Y.; Duan, X. Vertically Stacked MultiHeterostructures of Layered Materials for Logic Transistors and Complementary Inverters. Nat. Mater. 2013, 12, 246-252.

(5) Radisavljevic, B.; Radenovic, A.; Brivio, J.; Giacometti, V.; Kis, A. Single-Layer MoS 2 Transistors. Nat. Nanotechnol. 2011, 6, 147-150.

(6) Tang, B.; Yu, Z. G.; Huang, L.; Chai, J.; Wong, S. L.; Deng, J.; Yang, W.; Gong, H.; Wang, S.; Ang, K. W.; Zhang, Y. W.; Chi, D. Direct n- to p-Type Channel Conversion in Monolayer/Few-Layer $\mathrm{WS}_{2}$ Field-Effect Transistors by Atomic Nitrogen Treatment. ACS Nano 2018, 12, 2506-2513.

(7) Li, L.; Yu, Y.; Ye, G. J.; Ge, Q.; Ou, X.; Wu, H.; Feng, D.; Chen, X. H.; Zhang, Y. Black Phosphorus Field-Effect Transistors. Nat. Nanotechnol. 2014, 9, 372-377.

(8) Haratipour, N.; Namgung, S.; Oh, S. H.; Koester, S. J. Fundamental Limits on the Subthreshold Slope in Schottky Source/Drain Black Phosphorus Field-Effect Transistors. ACS Nano 2016, 10, 37913800 .

(9) Ma, Y.; Shen, C.; Zhang, A.; Chen, L.; Liu, Y.; Chen, J.; Liu, Q.; Li, Z.; Amer, M. R.; Nilges, T.; Abbas, A. N.; Zhou, C. Black Phosphorus Field-Effect Transistors with Work Function Tunable Contacts. ACS Nano 2017, 11, 7126-7133.

(10) Geim, A. K.; Grigorieva, I. V. Van der Waals Heterostructures. Nature 2013, 499, 419-425.

(11) Deng, Y.; Luo, Z.; Conrad, N. J.; Liu, H.; Gong, Y.; Najmaei, S.; Ajayan, P. M.; Lou, J.; Xu, X.; Ye, P. D. Black Phosphorus-Monolayer $\mathrm{MoS}_{2}$ van der Waals Heterojunction p-n Diode. ACS Nano 2014, 8, 8292-8299.

(12) Li, Y.; Wang, Y.; Huang, L.; Wang, X.; Li, X.; Deng, H. X.; Wei, Z.; Li, J. Anti-Ambipolar FieldEffect Transistors Based on Few-Layer 2D Transition Metal Dichalcogenides. ACS Appl. Mater. Interfaces 2016, 8, 15574-15581.

(13) Yan, R.; Fathipour, S.; Han, Y.; Song, B.; Xiao, S.; Li, M.; Ma, N.; Protasenko, V.; Muller, D. A.; Jena, D.; Xing, H. G. Esaki Diodes in van der Waals Heterojunctions with Broken-Gap Energy Band 
Alignment. Nano Lett. 2015, 15, 5791-5798.

(14) Nourbakhsh, A.; Zubair, A.; Dresselhaus, M. S.; Palacios, T. Transport Properties of a $\mathrm{MoS}_{2} / \mathrm{WSe}_{2}$ Heterojunction Transistor and Its Potential for Application. Nano Lett. 2016, 16, 1359-1366.

(15) Huang, M.; Li, S.; Zhang, Z.; Xiong, X.; Li, X.; Wu, Y. Multifunctional High-Performance van der Waals Heterostructures. Nat. Nanotechnol. 2017, 12, 1148-1154.

(16) Zhou, R.; Ostwal, V.; Appenzeller, Vertical versus Lateral Two-Dimensional Heterostructures: on the Topic of Atomically Abrupt p/n-Junctions. J. Nano Lett. 2017, 17, 4787-4792.

(17) Shim, J.; Oh, S.; Kang, D. H.; Jo, S. H.; Ali, M. H.; Choi, W. Y.; Heo, K.; Jeon, J.; Lee, S.; Kim, M.; Song, Y. J.; Park, J. H. Phosphorene/Rhenium Disulfide Heterojunction-Based Negative Differential Resistance Device for Multi-Valued Logic. Nat. Commun. 2016, 7, 13413.

(18) Lee, C. H.; Lee, G. H.; van der Zande, A. M.; Chen, W.; Li, Y.; Han, M.; Cui, X.; Arefe, G.; Nuckolls, C.; Heinz, T. F.; Guo, J.; Hone, J.; Kim, P. Atomically Thin p-n Junctions with van der Waals Heterointerfaces. Nat. Nanotechnol. 2014, 9, 676-681.

(19) Huo, N.; Yang, J.; Huang, L.; Wei, Z.; Li, S. S.; Wei, S. H.; Li, J. Tunable Polarity Behavior and Self-Driven Photoswitching in p-WSe $2 / \mathrm{n}-\mathrm{WS}_{2}$ Heterojunctions. Small 2015, 11, 5430-5438.

(20) Chen, P.; Xiang, J.; Yu, H.; zhang, J.; Xie, G.; Wu, S.; Lu, X.; Wang, G.; Zhao, J.; Wen, F.; Liu, Z.; Yang, R.; Shi, D.; Zhang, G. Gate Tunable $\mathrm{MoS}_{2}-$ Black Phosphorus Heterojunction Devices. 2D Mater. 2015, 2, 034009.

(21) Ye, L.; Li, H.; Chen, Z.; Xu, J. Near-Infrared Photodetector Based on $\mathrm{MoS}_{2} /$ Black Phosphorus Heterojunction. ACS Photonics 2016, 3, 692-699.

(22) Yan, F.; Zhao, L.; Patane, A.; Hu, P.; Wei, X.; Luo, W.; Zhang, D.; Lv, Q.; Feng, Q.; Shen, C.; Chang, K.; Eaves, L.; Wang, K. Fast, Multicolor Photodetection with Graphene-Contacted p-GaSe/nInSe van der Waals Heterostructures. Nanotechnology 2017, 28, 27 LT01.

(23) Wang, Y.; Zhou, W.-X.; Huang, L.; Xia, C.; Tang, L.-M.; Deng, H.-X.; Li, Y.; Chen, K.-Q.; Li, J.; Wei, Z. Light Induced Double ‘on' State Anti-Ambipolar Behavior and Self-Driven Photoswitching in $\mathrm{p}-\mathrm{WSe}_{2} / \mathrm{n}-\mathrm{SnS}_{2}$ Heterostructures. 2D Mater. 2017, 4, 025097.

(24) Doan, M. H.; Jin, Y.; Adhikari, S.; Lee, S.; Zhao, J.; Lim, S. C.; Lee, Y. H. Charge Transport in $\mathrm{MoS}_{2} / \mathrm{WSe}_{2}$ van der Waals Heterostructure with Tunable Inversion Layer. ACS Nano 2017, 11, 38323840 .

(25) Zhang, K.; Zhang, T.; Cheng, G.; Li, T.; Wang, S.; Wei, W.; Zhou, X.; Yu, W.; Sun, Y.; Wang, P.; Zhang, D.; Zeng, C.; Wang, X.; Hu, W.; Fan, H. J.; Shen, G.; Chen, X.; Duan, X.; Chang, K.; Dai, N. Interlayer Transition and Infrared Photodetection in Atomically Thin Type-II $\mathrm{MoTe}_{2} / \mathrm{MoS}_{2}$ van der Waals Heterostructures. ACS Nano 2016, 10, 3852-3858. 
(26) Yang, T.; Zheng, B.; Wang, Z.; Xu, T.; Pan, C.; Zou, J.; Zhang, X.; Qi, Z.; Liu, H.; Feng, Y.; Hu, W.; Miao, F.; Sun, L.; Duan, X.; Pan, A. Van der Waals Epitaxial Growth and Optoelectronics of LargeScale $\mathrm{WSe}_{2} / \mathrm{SnS}_{2}$ Vertical Bilayer p-n Junctions. Nat. Commun. 2017, 8, 1906.

(27) Wang, F.; Wang, Z.; Xu, K.; Wang, F.; Wang, Q.; Huang, Y.; Yin, L.; He, J. Tunable GaTe-MoS 2 van der Waals p-n Junctions with Novel Optoelectronic Performance. Nano Lett. 2015, 15, 7558-7566.

(28) Pezeshki, A.; Shokouh, S. H.; Nazari, T.; Oh, K.; Im, S. Electric and Photovoltaic Behavior of a Few-Layer alpha-MoTe $2 / \mathrm{MoS}_{2}$ Dichalcogenide Heterojunction. Adv. Mater. 2016, 28, 3216-3222.

(29) Yang, S.; Wu, M.; Wang, B.; Zhao, L. D.; Huang, L.; Jiang, C.; Wei, S. H. Enhanced Electrical and Optoelectronic Characteristics of Few-Layer Type-II SnSe/MoS 2 van der Waals Heterojunctions. ACS Appl. Mater. Interfaces 2017, 9, 42149-42155.

(30) Cheng, R.; Li, D.; Zhou, H.; Wang, C.; Yin, A.; Jiang, S.; Liu, Y.; Chen, Y.; Huang, Y.; Duan, X. Electroluminescence and Photocurrent Generation from Atomically Sharp WSe $2 / \mathrm{MoS}_{2}$ Heterojunction p-n Diodes. Nano Lett. 2014, 14, 5590-5597.

(31) Li, H.; Ye, L.; Xu, J. High-Performance Broadband Floating-Base Bipolar Phototransistor Based on $\mathrm{WSe}_{2} / \mathrm{BP} / \mathrm{MoS}_{2}$ Heterostructure. ACS Photonics 2017, 4, 823-829.

(32) Youngblood, N.; Chen, C.; Koester, S. J.; Li, M. Waveguide-Integrated Black Phosphorus Photodetector with High Responsivity and Low Dark Current. Nat. Photonics 2015, 9, 247-252.

(33) Miao, J.; Song, B.; Li, Q.; Cai, L.; Zhang, S.; Hu, W.; Dong, L.; Wang, C. Photothermal Effect Induced Negative Photoconductivity and High Responsivity in Flexible Black Phosphorus Transistors. ACS Nano 2017, 11, 6048-6056.

(34) Perumal, P.; Ulaganathan, R. K.; Sankar, R.; Liao, Y.-M.; Sun, T.-M.; Chu, M.-W.; Chou, F. C.; Chen, Y.-T.; Shih, M.-H.; Chen, Y.-F. Ultra-Thin Layered Ternary Single Crystals $\left[\operatorname{Sn}\left(\mathrm{S}_{\mathrm{x}} \mathrm{Se}_{(1-\mathrm{x})}\right)_{2}\right]$ with Bandgap Engineering for High Performance Phototransistors on Versatile Substrates. Adv. Funct. Mater. 2016, 26, 3630-3638.

(35) Yu, J.; Xu, C. Y.; Li, Y.; Zhou, F.; Chen, X. S.; Hu, P. A.; Zhen, L. Ternary $\operatorname{SnS}_{(2-\mathrm{x})} \operatorname{Se}_{(\mathrm{x})} \operatorname{Alloys}$ Nanosheets and Nanosheet Assemblies with Tunable Chemical Compositions and Band Gaps for Photodetector Applications. Sci. Rep. 2015, 5, 17109.

(36) Wang, Y.; Le Huang, L. H.; Li, B.; Shang, J.; Xia, C.; Fan, C.; Deng, H.-X.; Wei, Z.; Li, J. Composition-Tunable 2D $\mathrm{SnSe}_{2(1-\mathrm{x})} \mathrm{S}_{2 \mathrm{x}}$ Alloys Towards Efficient Bandgap Engineering and High Performance (Opto)Electronics. J. Mater. Chem. C 2017, 5, 84-90. 